\title{
Performance Assessment of Phenolic-based Non-Asbestos Organic Brake Friction Composite Materials with Different Abrasives
}

\author{
Tej Singh ${ }^{1}$, Amar Patnaik ${ }^{2}$, Ranchan Chauhan ${ }^{3}$, István Bíró ${ }^{4}$, \\ Endre Jánosi ${ }^{1}$, Gusztáv Fekete ${ }^{1}$
}

${ }^{1}$ Savaria Institute of Technology, Eötvös Loránd University, Károlyi Gáspár tér 4, H-9700 Szombathely, Hungary; sht@inf.elte.hu, je@inf.elte.hu, fg@inf.elte.hu

${ }^{2}$ Department of Mechanical Engineering, Malaviya National Institute of Technology Jaipur, Jawahar Lal Nehru Marg, Jhalana Gram, Malviya Nagar, Jaipur, Rajasthan-302017, India; apatnaik.mech@mnit.ac.in

${ }^{3}$ Department of Mechanical Engineering, Dr. B.R. Ambedkar National Institute of Technology Jalandhar, Grand Trunk Road, Bye pass, Jalandhar, Punjab-144011, India; chauhanr@nitj.ac.in

${ }^{4}$ Institute of Technology, University of Szeged, Mars tér 4, H-6724 Szeged, Hungary; biro-i@mk.u-szeged.hu

\footnotetext{
Abstract: This research article presents the effects of different abrasives (aluminium oxide, magnesium oxide, zinc oxide, iron oxide, silicon dioxide, titanium dioxide and zirconium dioxide) on tribological performance of non-asbestos brake friction materials. Therefore, friction composites with different abrasives were fabricated and characterized for various mechanical, chemical, and physical properties. The tribological properties of the friction composites were evaluated by running a European testing standard on a Krauss testing machine. It was seen that the different sorts of abrasives substantially affected the tribological performance of the friction composites. The highest values of friction coefficient (0.425), least friction fluctuations (0.252), highest stability coefficient (0.87) as well as the lowest fade ( 23\%) were obtained from the friction composites containing aluminum oxide as an abrasive. The recovery performance of all the friction composites was found to exceed $100 \%$ and the actual recovery level depends upon the type of abrasive. Contrary to the friction performance, the wear performance decreased for aluminum oxide and friction composite containing zinc oxide showed higher wear resistance.
}

Keywords: Polymer composites; Friction materials; Abrasive; Fade; Recovery; Wear 


\section{Introduction}

Composite materials used for automotive/locomotive brake systems usually contain property modifiers to enhance friction performance and to improve their wear resistance [1-4]. Abrasives, classified as property modifiers, are hard particles used in friction composite materials to enhance the friction performance [5]. They make the composites stable at elevated temperatures, while during the abrasive process, they remove the pyrolyzed surface film from the counterface disc $[6,7]$. A perfect selection of an abrasive along with its type, shape, amount, size, and its closeness with other components in the formulation contributes to the better execution of any friction composite [8]. During braking, abrasive particles work at the tribo-interface either as a two-body or three-body abrasion model, while having a significant effect on friction and wear performance [9, 10]. In addition, rotor wear or rotor thickness variation may also appear, which is produced by the rubbing of brake pads against the rotor during sliding. It must be mentioned that the main culprit of braking noise is most likely credited to this effect [11]. Therefore, a careful selection of abrasives for brake friction materials is vital as it is an essential ingredient for the enhancement of friction, controlling the wear of tribo-couple, friction fluctuation, and noise-related problems generated during braking [12].

The vast majority of the literature referenced the individual aspect of particular abrasives e.g. aluminium oxide [12], zircon [13], silicon carbide [14], quartz [15], silicon dioxide [16], while comparative features of abrasives were also reported [17]. V. Tomasek et al. [12] concluded that an abrasive (aluminium oxide, average size of 100 mesh) addition in friction formulation not only helps in minimizing the negative wear rate, but it also helps in upgrading the friction performance. While studying the size effect of zircon particles $(1,6,75$, and $150 \mu \mathrm{m}$, respectively), $\mathrm{K}$. H. Cho et al. [13] concluded that fade and friction instability remained the most significant in the friction composite having the smallest sized zircon particles with large frictional fluctuations and considerable wear. Fade resistance improved when coarse zircon particles were used. The composites exhibited excellent friction stability, however, the counter-face wear increased significantly as well. V. Matejka et al. [14] reported dissimilar results for silicon carbide filled composites. The authors studied the effect of silicon carbide particle size $(3,10$, and $40 \mu \mathrm{m}$, respectively) on the tribological attributes of non-asbestos brake materials. The authors observed that the presence of $3 \mu \mathrm{m}$ silicon carbide particles is responsible for highest friction performance accompanied with lowest fade. Authors observed that the specific wear rate decreases with increasing silicon carbide particle size. In another investigation, E. J. Lee et al. [15] explored the tribological behaviour of zircon $(13.7,133.1 \mu \mathrm{m})$ and quartz $(20.6,277.8 \mu \mathrm{m})$ filled friction composites where the addition of the quartz proved to be best from the coefficient of friction point of view. 
Moreover, they observed that smaller particles were proven effective in increasing the friction performance while large particles inclusion produced higher disc wear. In a recent study, W. Sun et al. [16] investigated the influence of different silicon dioxide abrasive particles, (10, 80, 180-700, 700-2000, and 2000-3000 $\mu \mathrm{m}$, respectively) in non-commercial friction composite materials. They observed that silicon dioxide particle size has a considerable influence on the friction mechanism of such composites. Higher contact films were observed for $10 \mu \mathrm{m}$ particle-based composites, which reported to stabilize the friction performance. Authors also suggested that $80 \mu \mathrm{m}$ particles usually work according to the threebody abrasive mechanism, 180-2000 $\mu \mathrm{m}$ sized particles can work as mixed twobody and three-body abrasive mechanisms, while $3000 \mu \mathrm{m}$ sized particles usually work according to two-body abrasive mechanism. In addition, Bijwe et al. [17] compared tribological performance of micro and nano-abrasives (aluminium oxide: $40-80 \mathrm{~nm}$ and $48-100 \mu \mathrm{m}$, silicon carbide: $50-60 \mathrm{~nm}$ and 3-100 $\mu \mathrm{m}$, silicon dioxide: $15 \mathrm{~nm}$ and $3 \mu \mathrm{m}$ ) of tribological performance of friction composites. They claimed that the formation of friction film on nano-abrasive filled composite mainly contributed in increased performance. B. K. Satapathy and J. Bijwe [18] investigated the influence of working parameters (sliding speed and braking pressure) on wear performance of different abrasives (silicon carbide, silicon dioxide, zircon dioxide, and aluminium oxide) filled friction materials. They revealed that comparatively to zircon dioxide, aluminium oxide and silicon dioxide-based friction composites remained less sensitive to working parameters.

Despite the above-mentioned studies, it is still challenging to describe the role of abrasives on the fade, recovery, friction stability, and variability aspects of brake friction materials. Therefore, it highly important to conduct a study to compare the tribo-performance of abrasives filled brake friction materials. Consequently, the present work is conducted to investigate the role of abrasives on the triboexecution of automotive brake materials. Tribo-execution of the brake materials was completely assessed utilizing ECR-90 run.

\section{Materials and Methods}

\subsection{Materials and Composite Fabrication}

Ingredients such as Kevlar fiber, phenolic resin, graphite, barium sulphate, lapinus fiber, potassium titanate, vermiculite and abrasives (aluminium oxide, magnesium oxide, zinc oxide, iron oxide, silicon dioxide, titanium dioxide and zirconium dioxide) according to the compositional variations, as presented in Table 1, were used in the fabrication of brake composites. The ingredients were purchased from Starke International New Delhi, India. 
The literature reveals that smaller sized abrasive particles develop a contact film, which stabilizes the friction performance and increase the wear resistance [14-17]. Hence, in this current study abrasives with an average size of 400 mesh were selected. The scanning electron micrographs of the selected abrasives are shown in Figure 1.

Table 1

Details of friction composites composition and nomenclature

\begin{tabular}{lllllllll}
\hline Composition (wt.\%) & \multicolumn{7}{c}{ Composite designation } \\
\cline { 2 - 8 } & MO-0 & MO-1 & MO-2 & MO-3 & MO-4 & MO-5 & MO-6 & MO-7 \\
\hline *Parent composition & 95 & 95 & 95 & 95 & 95 & 95 & 95 & 95 \\
Barium sulphate & 5 & 0 & 0 & 0 & 0 & 0 & 0 & 0 \\
Aluminium oxide & 0 & 5 & 0 & 0 & 0 & 0 & 0 & 0 \\
Magnesium oxide & 0 & 0 & 5 & 0 & 0 & 0 & 0 & 0 \\
Zinc oxide & 0 & 0 & 0 & 5 & 0 & 0 & 0 & 0 \\
Iron oxide & 0 & 0 & 0 & 0 & 5 & 0 & 0 & 0 \\
Silicon dioxide & 0 & 0 & 0 & 0 & 0 & 5 & 0 & 0 \\
Titanium dioxide & 0 & 0 & 0 & 0 & 0 & 0 & 5 & 0 \\
Zirconium dioxide & 0 & 0 & 0 & 0 & 0 & 0 & 0 & 5 \\
\hline
\end{tabular}

*Parent composition: Barium sulphate-50 wt.\%, graphite-5 wt.\%, fibers (Kevlar, lapinus; 1:2)-15 wt. $\%$, potassium titanate- 5 wt. $\%$, vermiculite -5 wt. $\%$ and phenolic resin- 15 wt. $\%$.
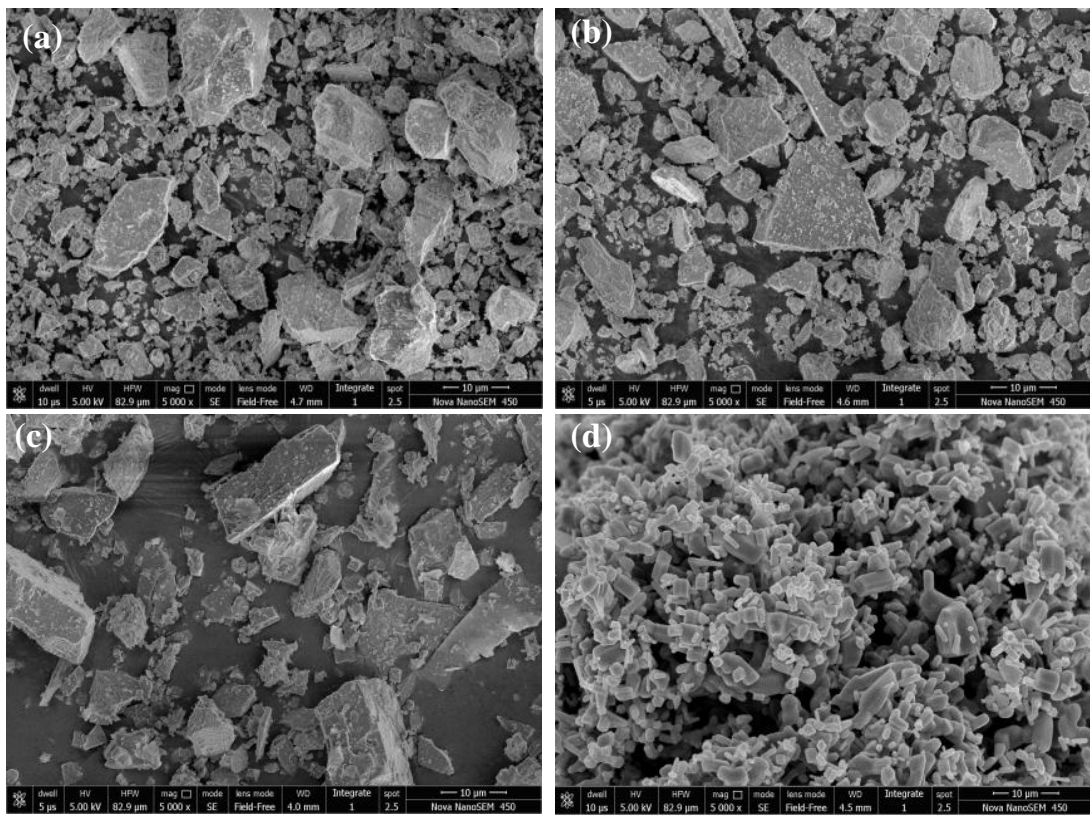

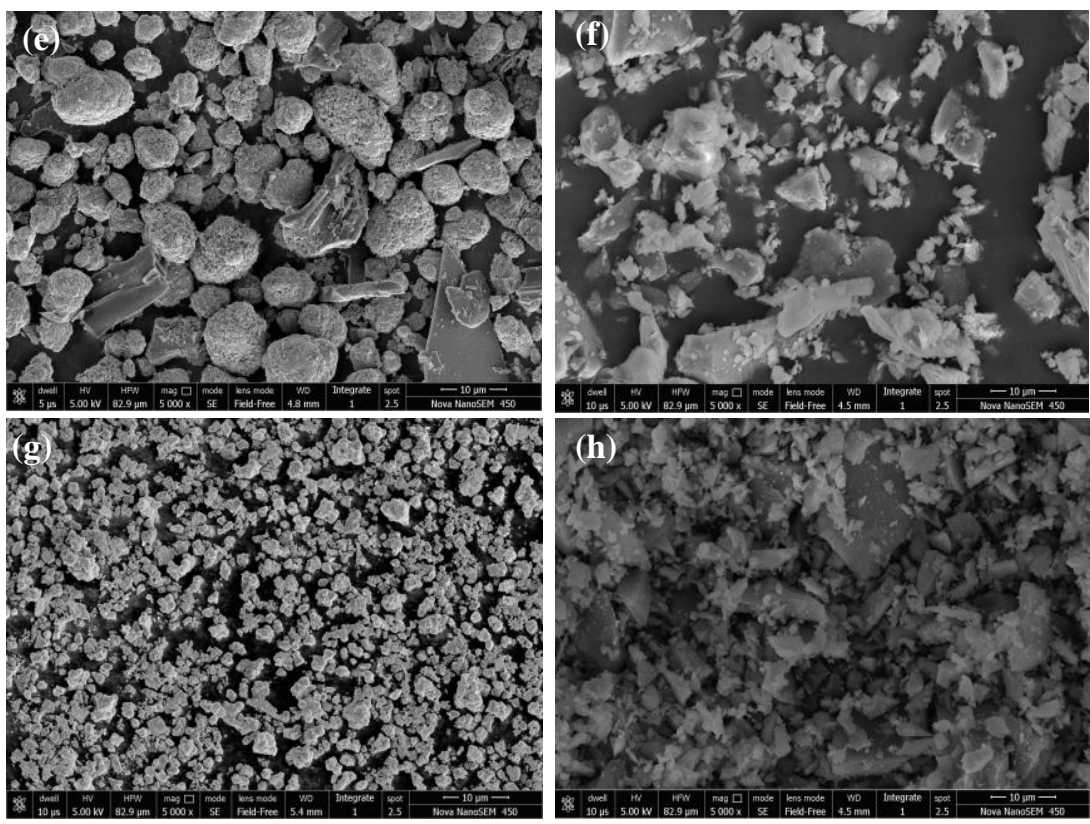

Figure 1

Scanning electron micrographs of (a) Barium sulphate (b) Aluminium oxide (c) Magnesium oxide (d) Zinc oxide (e) Iron oxide (f) Silicon dioxide (g) Titanium dioxide and (h) Zirconium oxide

The parent composition was always constant with $95 \mathrm{wt} . \%$ amount and $5 \mathrm{wt} . \%$ of abrasive was added to each composite. For comparison, an abrasive-free composite was also fabricated by adding $5 \mathrm{wt} . \%$ barium sulphate in the parent composition. To achieve mechanical isotropy, selected materials were blended in a mechanical mixer for $10 \mathrm{~min}$ [19]. The blend was put into a mold supported by the adhesive-coated steel back plates. The mold was then heat treated/cured at $155{ }^{\circ} \mathrm{C}$ of temperature for $10 \mathrm{~min}$ with $15 \mathrm{MPa}$ pressure using a compressionmolding machine [20]. After that, the brake pad composites were relieved in an oven at $170{ }^{\circ} \mathrm{C}$ for $4 \mathrm{~h}$ and used for different (mechanical, chemical, physical and tribological) characterizations.

\subsection{Characterization of Mechanical, Chemical and Physical Properties}

The density of the composites was determined with the help of the Archimedes principle, whereas a standard protocol JIS D 4418:1996 was used for porosity measurement [21]. The ash content was determined by scorching the composite specimen at $\sim 800{ }^{\circ} \mathrm{C}$ of temperature. Soxhlet extraction was used for determining the acetone extraction (quantity of uncured resin) present in the composites. 
Hardness investigation was done with the help of Rockwell hardness tester according to the ASTM D785 standards. Shear strength of the fabricated friction composite specimens was measured according to ISO 6312 whereas ISO 6310 was used for compressibility measurements.

\subsection{Tribological Properties Evaluation}

The tribological properties of the developed composites were assessed by running ECR (Economic Commission for Europe) R-90 procedure on Krauss machine. The detailed description of the machine and testing schedule is reported elsewhere [18-20]. The nominal braking pressure of $2 \mathrm{MPa}$ and a speed of $660 \mathrm{rpm}$ on the disc were applied following the regulation of the standard ECR R-90 test protocol which consists of seven cycles of ten brakes each for tribological properties assessment. The braking duration was $10 \mathrm{~s}$ and a $10 \mathrm{~s}$ interval was maintained between two successive brakes. Prior to seven test cycles, a bedding cycle of 30 brakes was initiated to ensure uniform contact between brake pad and disc. After the bedding cycle, the cold friction cycle began with $45{ }^{\circ} \mathrm{C}$ initial temperature while fans were employed to control the generated frictional heat of the disc. The cold cycle was trailed by five back-to-back fade cycles. At the beginning of each fade cycle, the disc temperature was kept under $100{ }^{\circ} \mathrm{C}$ and then permitted to rise progressively until the end of 10 brakes. Finally, after completion of the fifth fade cycle, the recovery cycle started by keeping up comparative conditions for fade cycles with air fan on. The wear of the friction composite was measured in terms of thickness and weight loss. For every composite specimen, three trials were conducted and the outcomes were inside $95 \%$ of certainty level.

\section{Results and Discussion}

\subsection{Results of Mechanical, Physical and Chemical Properties}

The evaluated properties of the composites specimens are presented in Table 2. It was observed that density $(\sim 2.26 \pm 0.04 \mathrm{~g} / \mathrm{cm} 3)$ and porosity $(\sim 7.42 \pm 0.72 \%)$ of the tested composites remained broadly unaffected with compositional variations. On the other hand, the acetone extraction was found to be negligible and nearly equivalent $(\sim 0.32 \pm 0.09 \%)$ in all the tested composites and might be ascribed to the presence of an equal amount of organic content. Furthermore, the unchanged organic content in the composites resulted in almost equivalent ash content $\sim 72.18$ $\pm 1.96 \%$. Hardness, compressibility and shear strength of the composites have been seen to stay in the range of $\sim 104 \pm 2.5$ in the L-scale, $\sim 0.90 \pm 0.12 \%$ and $\sim 836 \pm 74$ kgf respectively. 
Table 2

Physical, mechanical and chemical properties of friction composites

\begin{tabular}{lllllllll}
\hline Properties & MO-0 & MO-1 & MO-2 & MO-3 & MO-4 & MO-5 & MO-6 & MO-7 \\
\hline Density $\left(\mathrm{g} / \mathrm{cm}^{3}\right)$ & 2.28 & 2.27 & 2.24 & 2.30 & 2.29 & 2.22 & 2.23 & 2.30 \\
Porosity $(\%)$ & 7.56 & 7.78 & 7.44 & 6.70 & 8.14 & 7.84 & 7.16 & 7.18 \\
Acetone extraction (\%) & 0.36 & 0.42 & 0.27 & 0.23 & 0.38 & 0.42 & 0.26 & 0.34 \\
Ash content (\%) & 70.22 & 70.81 & 74.02 & 73.01 & 71.69 & 73.21 & 73.06 & 74.14 \\
Shear strength (kgf) & 762 & 875 & 890 & 795 & 910 & 825 & 900 & 835 \\
Compressibility (\%) & 0.78 & 0.96 & 0.80 & 0.86 & 1.02 & 0.92 & 0.98 & 0.82 \\
Hardness (HRL) & 101.50 & 102.83 & 103.67 & 102.33 & 106.5 & 103.83 & 104.50 & 102.5 \\
\hline
\end{tabular}

\subsection{Braking Performance Response of the Composites}

The coefficient friction $(\mu)$ and the corresponding temperature of the disc with respect to braking cycles (cold, fade and recovery) are depicted in Figure 2. It is clear that all the composites displaying the fluctuating/unsteady frictional response in cold cycle. As observed in Figure 2 a for MO-0, the $\mu$ rose continuously until the third braking, and then it began diminishing until the $10^{\text {th }}$ braking. This phenomenon was observed in the first three fade cycles, while some enhancement appeared later in two fade cycles. From Figure 2b, one can see that the first fade cycle behaviour of MO-1 and MO-0 is similar. However, in further fade cycles, the $\mu$ curve becomes flattered demonstrating good performance of MO- 1 . While for friction composite MO-2 (Figure 2c) appreciable fade was seen after the third braking onwards for the first two fade cycles, while the sharpness of the slope diminished and completely vanished during the fourth and the fifth fade cycles. For MO-3 and MO-4 (Figures 2d and 2e) composites, the friction performance remained wildly fluctuating.

Abrupt friction peaking with steeper friction-decay was observed in the first four fade cycles of MO-3 and MO-4 composites. However, in the fifth fade run, the $\mu$ response showed some signs of improvement. In the case of friction composite MO-5, as seen from Figure $2 \mathrm{f}, \mu$ climbed continuously until the third braking and it began diminishing sharply until the $10^{\text {th }}$ braking for the first three fade cycles and it demonstrated some enhancement in the last two fade cycles. Severe fade for MO-6 (Figure 2g) was seen in the first two fade runs after the third braking. From the third fade run, onwards a consistent friction build-up was observed with adequate friction-peaking effects without any substantial friction-decay. For MO-7 (Figure $2 \mathrm{~h}$ ), in the first fade cycle fade was observed after the third while for the next two fade cycles fade was seen after fourth braking. In the last two fade cycles of MO-7, the $\mu$ curve becomes flattered indicating improved fade performance. 

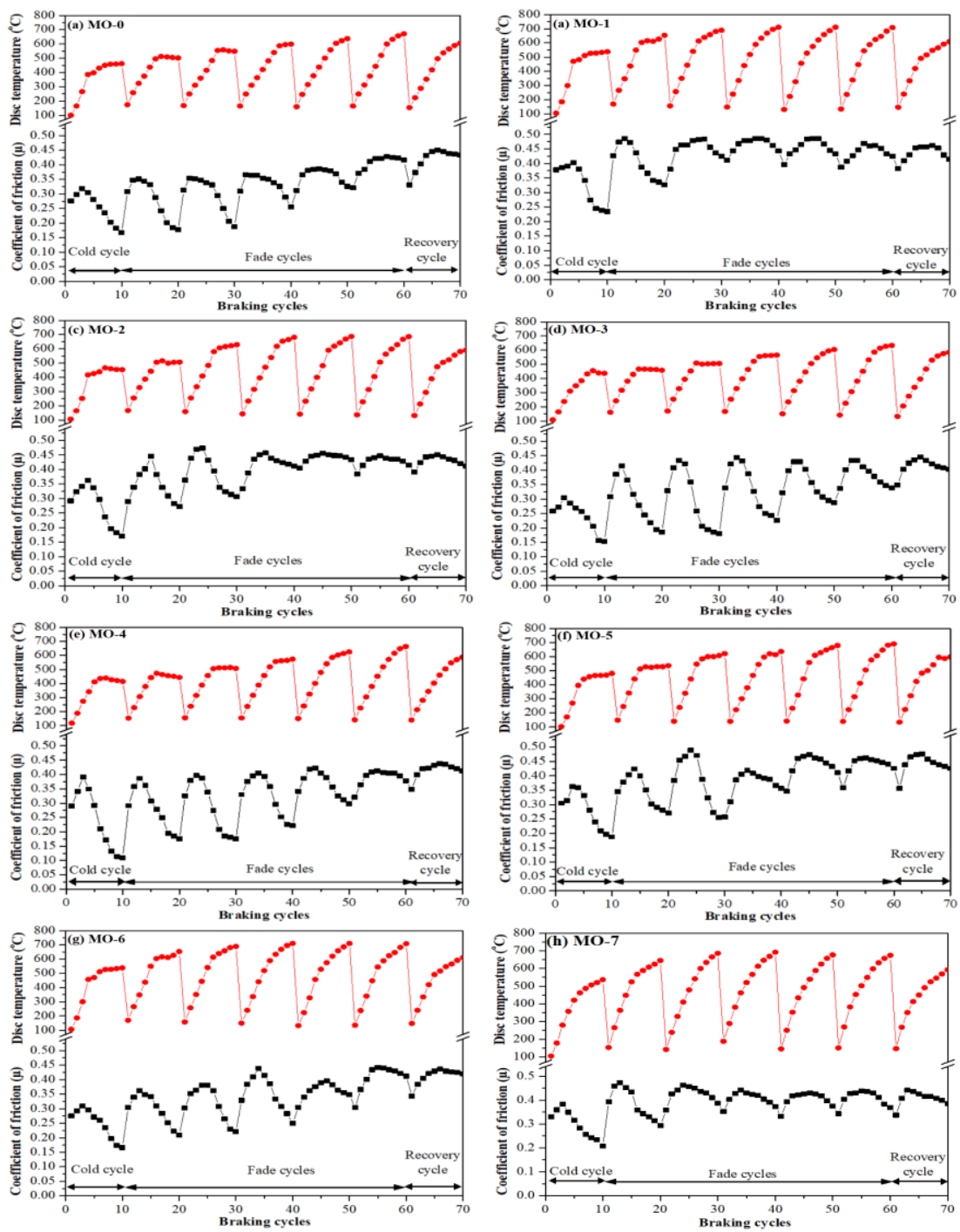

Figure 2

The coefficient of friction and disc temperature of the composites with respect to braking cycles

\section{3 $\mu$-performance $\left(\mu_{P}\right), \mu$-fade $\left(\mu_{F}\right), \mu$-recovery $\left(\mu_{R}\right)$ and Friction Fluctuations $\left(\mu_{\max }-\mu_{\min }\right)$}

The $\mu_{\mathrm{P}}, \mu_{\mathrm{F}}$ and $\mu_{\mathrm{R}}$ outcomes of the tested composites are depicted in Figure 3. $\mu_{\mathrm{P}}$ is the average value of $\mu$ registered for seven cycles whereas, $\mu_{F}$ and $\mu_{R}$ are the minimum and maximum $\mu$ values registered for the fade and recovery cycles 
respectively $[22,23]$. In friction composite containing no abrasive i.e. MO-0, the frictional outputs $\left(\mu_{\mathrm{P}}\right.$ and $\left.\mu_{\mathrm{F}}\right)$ reflected at 0.335 and 0.178 respectively. However, the addition of abrasives has caused discrete changes in terms of their $\mu_{\mathrm{P}}$ and $\mu_{\mathrm{F}}$ outputs. It was observed that the inclusion of zinc oxide, iron oxide, and titanium dioxide resulted in almost similar $\mu_{\mathrm{P}}(0.328-0.344)$ and $\mu_{\mathrm{F}}(0.175-0.209)$ outputs. In addition, magnesium oxide, silicon dioxide and zirconium dioxide-based formulations resulted in higher $\mu_{\mathrm{P}}(0.385-0.390)$ and $\mu_{\mathrm{F}}(0.270-0.284)$ outputs while $\mu_{\mathrm{P}}(0.425)$ and $\mu_{\mathrm{F}}(0.326)$ were observed to be the highest for the aluminium oxide-based friction composites.

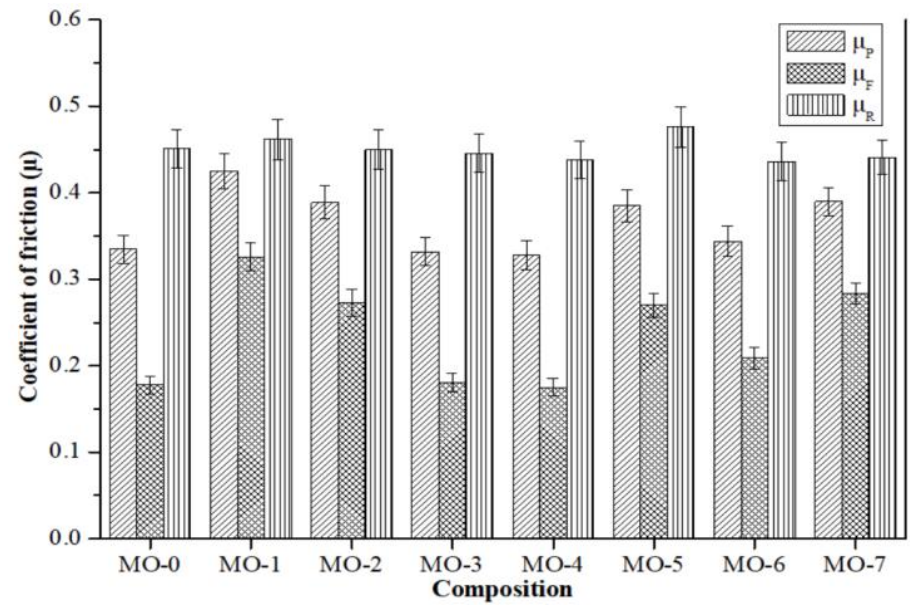

Figure 3

$\mu_{P}, \mu_{F}$ and $\mu_{R}$ performance of the composites

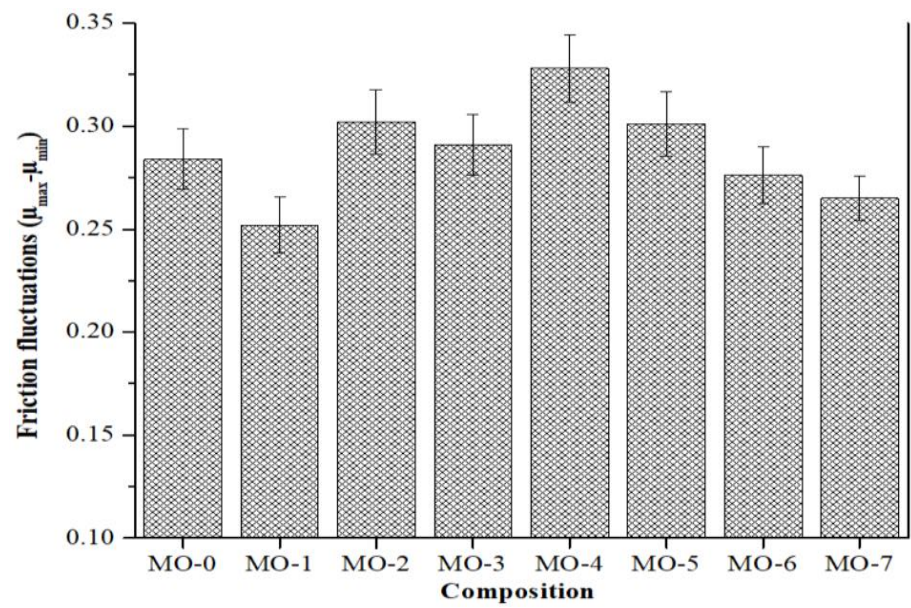

Figure 4

Friction fluctuations of the composites 
Further, the $\mu_{R}$ was observed in the range of $0.436-0.476$, which remained fairly comparable for all the friction composites irrespective of the abrasive. Such a performance theoretically suggests a similarity in the friction film creation/restoration process, which is initiated by organic ingredients and graphite having the same content in the friction formulations [24]. The frictional fluctuations as indicated by $\mu_{\max }-\mu_{\min }$ have been seen to be reliant upon the composition (Figure 4). It was seen that the composite that had the highest coefficient of friction (0.425) brought about the least friction fluctuations $(0.252)$ as compared to the other investigated composites. The addition of aluminium oxide to friction material formulations not only helps in reducing the frictional fluctuations, i.e. $\mu_{\max }-\mu_{\min }$ but also resulted in enhanced $\mu_{\mathrm{P}}$ and $\mu_{\mathrm{F}}$ with a good recovery response.

\subsection{Friction Stability and Variability}

The stability and variability coefficients of the friction composite are presented in Figure 5. These two parameters were significant for the assessment of friction composite materials and calculated as follows [25, 26]:

Stability coefficient $=\frac{\mu_{\mathrm{P}}}{\mu_{\max }}$

Variability coefficient $=\frac{\mu_{\min }}{\mu_{\max }}$

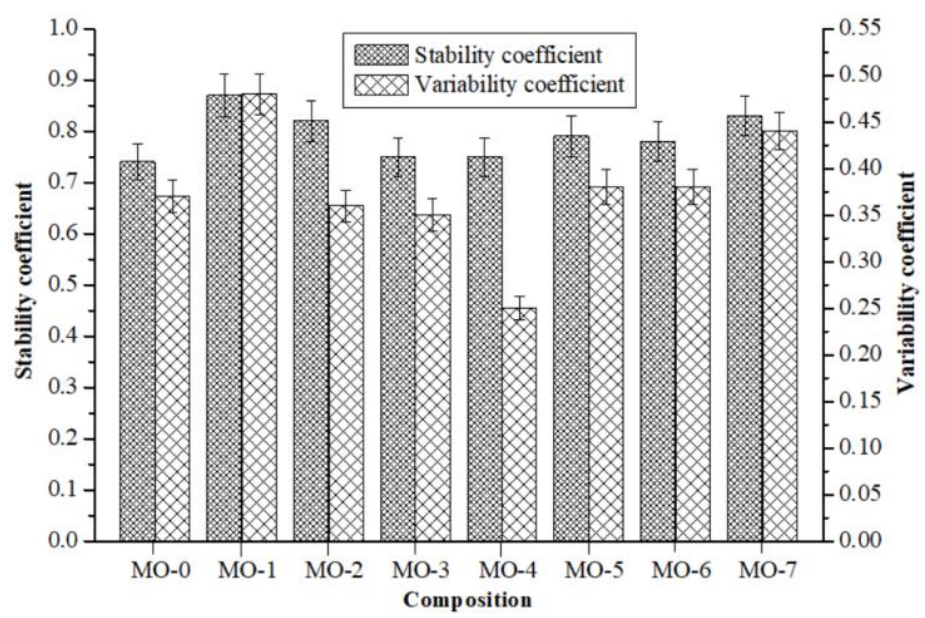

Figure 5

Stability and variability coefficients of the composites 
A friction composite is rated superior for higher values of stability and variability coefficients. It was seen that the aluminium oxide-based composite, i.e. MO-1 demonstrating the highest friction performance also resulted in higher stability $(0.87)$ and variability coefficients $(0.48)$. The stability and variability coefficients were remaining lowest for MO-0 and MO-4 composites. The friction stability stayed nearly 0.74 for MO-0; however, the stability of various explored composites has appeared well above 0.75 . This indicates that with the addition of abrasives the friction film stability/integrity is improved and the degree of heterogeneity in the friction layer will in general decline. It was observed that the friction composite MO-1 had the highest $\mu$-performance resulting in the higher stability and variability coefficient with less fluctuation when compared to the other friction composites.

\subsection{Fade, Recovery and Disc Temperature}

The performance of investigated friction composites in terms of $\%$-fade and \%recovery is presented in Figure 6 . It is seen that the $\%$-fade remains maximum $(\sim 47 \%)$ for the composition MO-0, whereas for MO-1, which has aluminium oxide as abrasive, it decreases drastically and the fade remains the lowest $(\sim 23 \%)$. The \%-recovery of the investigated composites remains appreciably high ( 108$135 \%)$ as prescribed by IS-2742 standard. Strikingly both the \%-fade and \%recovery remained highest for MO-0 composite demonstrating that the faderecovery characteristics were greatly affected by the nature of friction film formation. The abrasive particles in the composition try to grind down the film formed on the surface by the decomposition of the organic constituents.

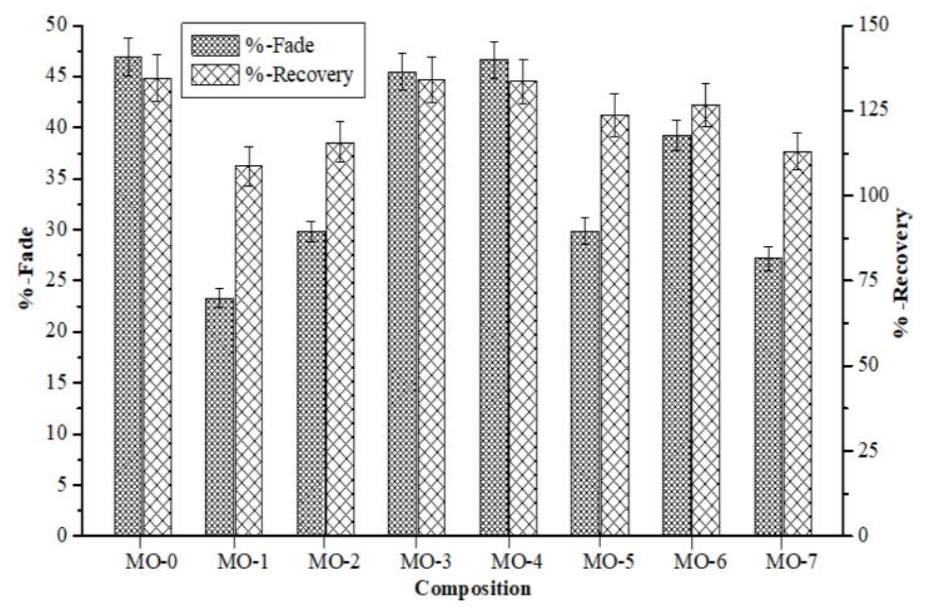

Figure 6

Variation of $\%$-fade and \%-recovery of the composites 
The lowest $\%$-fade $(\sim 23 \%)$ in spite of the highest disc temperature might be ascribed to the presence of hard aluminium oxide that minimizes/arrest the temperature-induced friction decay effect. The \%-recovery performance of the studied friction composites specimens stayed in between 108-135\%. The composite, MO-0 without any abrasive showing maximum fade $(\sim 4 \%)$, and it also exhibit the maximum recovery $(\sim 135 \%)$. The \%-recovery performance mainly depends upon the friction/contact film deposited on the composite surface after the completion of the fifth fade cycle. Within the initial few brakings of the recovery cycle, this friction film will disintegrate into wear debris. With further brakings, these wear debris become entrapped between the composite and disc interface, which will enhance the friction performance according to the third body abrasion mechanism [27, 28]. Hence, the abrasive not only improves the $\mu$ performance of the friction composites, but it also improves the $\mu$-fade. The level of improvement depends upon the type of abrasive used in the composition. Moreover, the disc temperatures remained highest for MO- 1 composite $\left(710{ }^{\circ} \mathrm{C}\right)$, closely followed by MO-2, MO-5, and MO-7 (689.5 $\pm 2.5^{\circ} \mathrm{C}$, See Figure 7). The disc temperature remained lowest for the composite MO-3 $\left(633{ }^{\circ} \mathrm{C}\right)$ whereas for composites MO-0, MO-4, and MO- 6 the disc temperature remained between 668 $\pm 4{ }^{\circ} \mathrm{C}$. This temperature $\left(687-710{ }^{\circ} \mathrm{C}\right)$ build-up phenomenon in aluminium oxide (MO-1), magnesium oxide (MO-2), silicon dioxide (MO-5) and zirconium dioxide (MO-7) filled composites was sufficiently complemented by a higher $\mu$ performance $(0.385-0.425)$ response with reduced \%-fade $(\sim 23-30 \%)$.

In addition, MO-0, MO-3, MO-4, and MO-5 composites have indicated higher degrees of $\%$-fade $(\sim 40-47 \%)$, which additionally had an immediate association with lower disc temperature $\left(633-672{ }^{\circ} \mathrm{C}\right)$. Thus, \%-fade and \%-recovery performance attributes were observed to be reliant on the utilized abrasives and they played a central role as performance determinants.

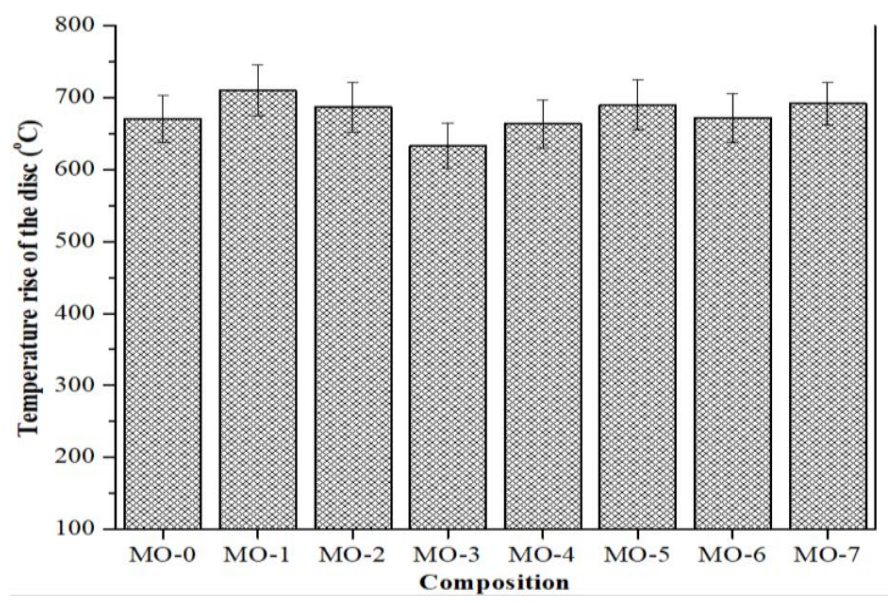

Figure 7

Disc temperature of the composites 


\subsection{Wear Performance of Composites}

The wear performance (in terms of weight and thickness loss) is depicted in Figure 8. In general, component wear is obtained by normalizing the weight and thickness change of composite specimen before and after testing. The wear of composite MO-1 with aluminium oxide was the highest and that of composite MO-1 with zinc oxide was the lowest. The ingredients with high hardness such as aluminium oxide, magnesium oxide, silicon dioxide, and zirconium dioxide increase the wear of the friction composites due to their abrasive action against the sliding junction. The improved wear performance of MO-3 with zinc oxide may be due to its inherent wear resistance with a lower hardness that prevents the abrasion effect [29].

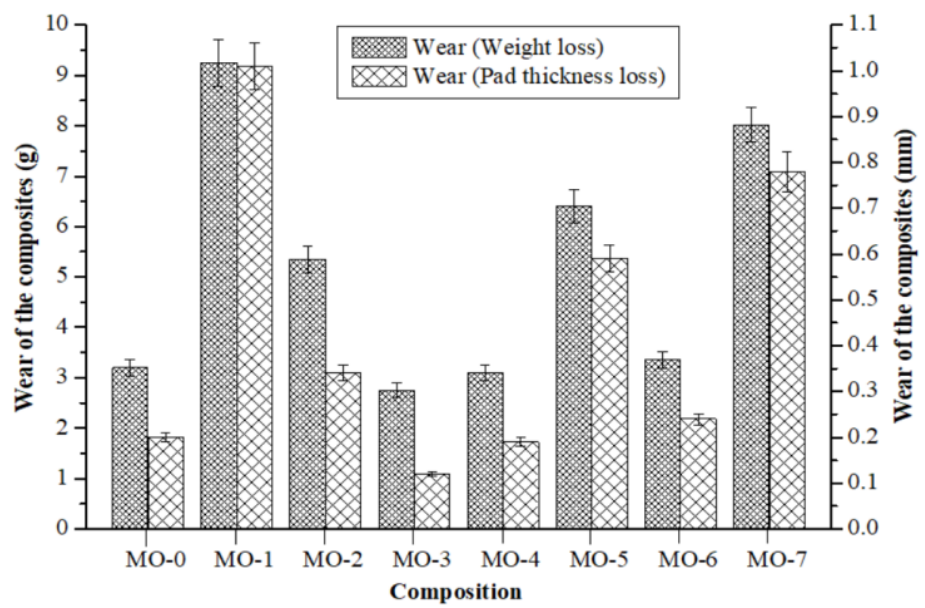

Figure 8

Wear of the composite

\subsection{Worn Surface Morphology}

The wear performance of the composite was further correlated with its worn surface as presented in Figure 9. It was reported in the literature that the extent of wear was mainly dependent upon the formation of contact plateaus (primary and secondary) on the composite surface [30-32]. The primary contact plateaus were originated by the embedment of hard ingredients in the composite surface. The secondary contact plateaus (generally the smooth glazy patches) were originated by the degradation of organic ingredients. The primary contact plateaus were reported to enhance the friction performance while secondary contact plateaus were reported to enhance wear performance of the composites [33-36]. 


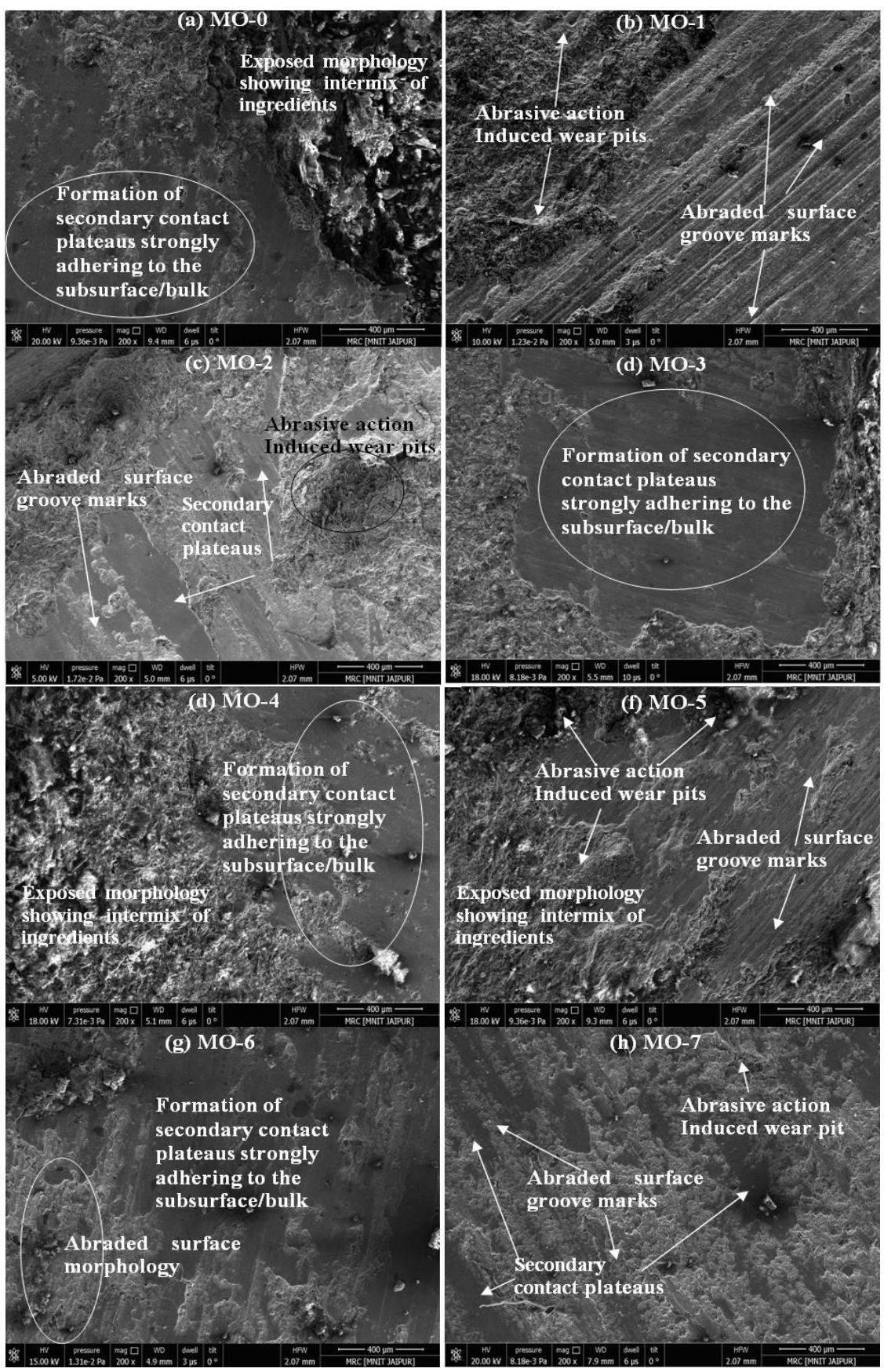

Figure 9

Worn surface morphology of the composites 
It was observed that aluminium oxide (MO-1, Figure 9b), magnesium oxide (MO2, Figure 9c), silicon dioxide (MO-5, Figure 9f) and zirconium dioxide (MO-7, Figure $9 \mathrm{~h}$ ) inclusion in friction composites resulted in a deterioration in the topography of surfaces. The abrasive action led to the formation of wear pits in these composites indicating that harder constituents encountered during braking result in a higher friction level $(\sim 0.405 \pm 0.020)$ with lower wear performance $(\sim 7.83 \pm 1.42 \mathrm{~g})$. The worn surface of the composite MO-1 (Figure 9b) demonstrated harsh surface topography with considerably less degree of secondary contact plateaus suggesting a higher wear rate. Furthermore, with magnesium oxide (MO-2, Figure 9c), silicon dioxide (MO-5, Figure 9f), and zirconium dioxide (MO-7, Figure $9 \mathrm{~h}$ ) the worn surface topography remains rough. It must be mentioned, that the extent of secondary plateaus increased while the deterioration of primary ingredients decreased, resulting in their increased wear performance to that of an aluminium oxide-based composite. It can be seen that there were no significant differences in the worn surface topographies of the friction composites MO-0 (Figure 9a), MO-4 (Figure 9e) and MO-6 (Figure 9g). The worn surfaces of these composites showed smooth surface topography and higher secondary contact plateaus compared with the friction composites MO-1, MO-2, MO-5, and MO-7 resulting in their moderate wear rate. The worn surface of the friction composite MO-3 (Figure 9d) was covered extensively with the secondary contact plateaus. These secondary plateaus covered the composite surface to a larger amount, which minimizes the loss of the ingredients during sliding resulting in the lowest wear and the second-lowest friction performance.

\section{Conclusions}

The physical, mechanical, chemical, and tribological properties of brake friction composites containing different types of abrasives have been evaluated as per industrial norms. The following conclusions were achieved from the above investigations:

- The investigated physical, chemical, and mechanical properties broadly remain unaffected and do not follow any specific trend.

- The developed composites showed a coefficient of friction in the range of $0.30-0.45$, which is in the desired range of industrial practice. The highest performance for the coefficient of friction, best fade performance, least friction fluctuations with the best stability and variability coefficient values were obtained in the composite containing aluminium oxide as abrasive.

- Parent composition suffered highest the fade and exhibits the highest recovery, which was reduced to their lowest level by the inclusion of aluminium oxide. Interestingly zinc oxide and iron oxide did not influence the fade and recovery properties of the parent composition appreciably. Whereas magnesium oxide, silicon dioxide, and zirconium dioxide-based composites exhibit fade and recovery performance next to aluminium oxide based 
composites. All the composites irrespective of the abrasives have shown more than $100 \%$ recovery.

- The inclusion of zinc oxide and iron oxide helped improve the wear performance of the parent composition. Zinc oxide performed to be the best in this respect, while the incorporation of aluminium oxide proved detrimental.

Overall, it was concluded that the type of abrasive in brake friction composite materials influences the tribological properties drastically. Aluminium oxide appeared to be the best performing abrasive followed by zirconium dioxide, magnesium oxide and silicon dioxide.

\section{Acknowledgment}

This paper was supported by: Eötvös Loránd University, Malaviya National Institute of Technology Jaipur, Dr. B. R. Ambedkar National Institute of Technology Jalandhar, and the University of Szeged.

\section{References}

[1] J. Bijwe: Composites as friction materials: Recent developments in nonasbestos fibre reinforced friction materials- a review, Polymer Composites, Vol. 18, No. 3, 1997, pp. 378-396

[2] W. Zhen-yu, W. Jie, C. Feng-hong, M. Yun-hai, T. Singh, G. Fekete: Influence of banana fiber on physicomechanical and tribological properties of phenolic based friction composites, Materials Research Express, Vol. 6, 2019, 075103

[3] P. Wasilewski: Experimental study on the effect of formulation modification on the properties of organic composite railway brake shoe, Wear, Vol. 390-391, 2017, pp. 283-294

[4] L. Lendvai, D. Brenn: Mechanical, Morphological and Thermal Characterization of Compatibilized Poly(lactic acid)/Thermoplastic Starch Blends, Acta Technica Jaurinensis, Vol. 13, No. 1, 2020, pp. 1-13

[5] T. Singh: Tribo-performance evaluation of fibre reinforced and nano-filled composite friction materials, PhD Thesis, N.I.T. Hamirpur, 2013

[6] M. Vlastimil, S. M. Gražyna, Y. Ma, Y. Lu: Semimetallic brake friction materials containing $\mathrm{ZrSiO}_{4}$ : friction performance and friction layers evaluation, Journal of Composite Materials, Vol. 43, No. 13, 2009, pp. 1421-1434

[7] I. Sugozu, I. Mutlu, K. B. Sugozu: The effect of ulexite to the tribological properties of brake lining materials, Polymer Composites, Vol. 39, No. 1, 2018, pp. 55-62

[8] R. Yun, G. M. Simha, L. Yafei: Performance and evaluation of nonasbestos organic brake friction composites with $\mathrm{SiC}$ particles as an abrasive, Journal of Composite Materials, Vol. 45, No. 15, 2011, pp. 1585-1593 
[9] T. Sasada, M. Oike, N. Emori: The effect of abrasive grain size on the transition between abrasive and adhesive wear, Wear, Vol. 97, 1984, pp. 291-302

[10] T. Singh, R. Chauhan, A. Patnaik, B. Gangil, R. Nain, A. Kumar: Parametric study and optimization of multiwalled carbon nanotube filled friction composite materials using taguchi method, Polymer Composites, Vo. 39, No. S2, 2018, pp. E1109-E1117

[11] Y. Ma, G. S. Martynkova, M. Valaskova, M. Vlastimil, L. Yafei: Effects of $\mathrm{ZrSiO}_{4}$ in non-metallic brake friction materials on friction performance, Tribology International, Vol. 41, 2008, pp. 166-174

[12] V. Tomasek, G. Kratosova, R. Yun, F. Yanli, L. Yafei: Effects of alumina in non-metallic brake friction materials on friction performance, Journal of Materials Science, Vol. 44, 2009, pp. 266-273

[13] K. H. Cho, H. Jang, Y. S. Hong, S. J. Kim, R. H. Basch, J. W. Fash: The size effect of zircon particles on the friction characteristics of brake lining materials, Wear, Vol. 264, 2008, pp. 291-297

[14] V. Matejka, Y. Lu, L. Jiao, H. Li, S. M. Gražyna, T. Vladimír: Effects of silicon carbide particle sizes on friction-wear properties of friction composites designed for car brake lining applications, Tribology International, Vol. 43, 2010, pp. 144-151

[15] E. J. Lee, H. J. Hwang, W. G. Lee, K. H. Cho, H. Jang: Morphology and toughness of abrasive particles and their effects on the friction and wear of friction materials: a case study with zircon and quartz, Tribology Letters, Vol. 37, No. 3, 2009, pp. 637-644

[16] W. Sun, W. Zhou, J. Liu, F. Xuesong, C. Guoqing, Y. Shan: The size effect of $\mathrm{SiO}_{2}$ particles on friction mechanisms of a composite friction material, Tribology Letters, Vol. 66, 2018, p. 35

[17] J. Bijwe, N. Aranganathan, S. Sharma, N. Dureja, R. Kumar: Nanoabrasives in friction materials-influence on tribological properties, Wear, Vol. 296, 2012, pp. 693-701

[18] B. K. Satapathy, J. Bijwe: Wear data analysis of friction materials to investigate the simultaneous influence of operating parameters and compositions, Wear, Vol. 256, 2004, pp. 797-804

[19] T. Singh, A. Tiwari, A. Patnaik, R. Chauhan, S. Ali: Influence of wollastonite shape and amount on tribo-performance of non-asbestos organic brake friction composites, Wear, Vol. 386-387, 2017, pp. 157-164

[20] T. Singh, A. Patnaik, R. Chauhan, P. Chauhan: Selection of brake friction materials using hybrid analytical hierarchy process and vise Kriterijumska Optimizacija Kompromisno Resenje approach, Polymer Composites, Vol. 39, 2018, pp. 1655-1662 
[21] T. Singh, A. Patnaik: Thermo-mechanical and tribological properties of multi-walled carbon nanotubes filled friction composite materials, Polymer Composites, Vol. 38, 2017, pp. 1183-1193

[22] J. Bijwe, M. Kumar: Optimization of steel wool contents in non-asbestos organic (NAO) friction composites for best combination of thermal conductivity and tribo-performance, Wear, Vol. 263, 2007, pp. 1243-1248

[23] N. Kumar, T. Singh, J. S. Grewal, A. Patnaik, G. Fekete: Experimental investigation on the physical, mechanical and tribological properties of hemp fiber-based non-asbestos organic brake friction composites, Materials Research Express, Vol. 6, 2019, 085710

[24] N. Dadkar, B. S. Tomar, B. K. Satapathy: Evaluation of flyash-filled and aramid fibre reinforced hybrid polymer matrix composites (PMC) for friction braking applications, Materials and Design, Vol. 30, 2009, pp. 4369-4376

[25] N. Kumar, T. Singh, J. S. Grewal, A. Patnaik, G. Fekete: A novel hybrid AHP-SAW approach for optimal selection of natural fiber reinforced nonasbestos organic brake friction composites, Materials Research Express, Vol. 6, 2019, p. 065701

[26] T. Singh, A. Patnaik, G. Fekete, R. Chauhan, B. Gangil: Application of hybrid analytical hierarchy process and complex proportional assessment approach for optimal design of brake friction materials, Polymer Composites, Vol. 40, 2019, pp. 1602-1608

[27] A. Tiwari, H. S. Jaggi, R. K. Kachhap, B. K. Satapathy, S. N. Maiti, B. S. Tomar: Comparative performance assessment of cenosphere and barium sulphate based friction composites, Wear, Vol. 309, 2014, pp. 259-268

[28] Y. Liu, Y. Ma, J. Che, L. Duanmu, J. Zhuang, J. Tong: Natural fibre reinforced non-asbestos organic non-metallic friction composites: effect of abaca fibre on mechanical and tribological behaviour. Materials Research Express, Vol. 5, 2018, 055101

[29] K. S. Akant, Siddhartha, S. Yadav, P. K. Singh, Repercussion of manufacturing techniques on mechanical and wear peculiarity of $\mathrm{ZnO}$ particulate-filled polyester composites, Polyester Composites, Vol. 39, No. 3, 2018, pp. 654-667

[30] Nidhi, J. Bijwe: NBR-modified resin in fade and recovery module in nonasbestos organic (NAO) friction materials, Tribology Letters, Vol. 27, 2007, pp. 189-196

[31] P. D. Neis, N. F. Ferreira, G. Fekete, L. T. Matozo, D. Masotti: Towards a better understanding of the structures existing on the surface of brake pads, Tribology International, Vol. 105, 2017, pp. 135-147 
[32] I. Hatos, I. Fekete, T. Ibriksz, G. J. Kovács, B. M. Maros, H. Hajnalka: Surface modification and wear properties of direct metal laser sintered hybrid tools used in moulds. Strojniski Vestnik - Journal of Mechanical Engineering, Vol. 64, 2018, pp. 121-129

[33] Y. Liu, J. Xie, N. Wu, L. Wang, Y. Ma, J. Tong: Influence of silane treatment on the mechanical, tribological and morphological properties of corn stalk fiber reinforced polymer composites. Tribology International, Vol. 131, 2019, pp. 398-405

[34] T. Singh, M. K. Rathi, A. Patnaik, R. Chauhan, S. Ali, G. Fekete: Application of waste tire rubber particles in non-asbestos organic brake friction composite materials, Materials Research Express, Vol. 6, 2019, 035703

[35] P. C. Verma, R. Ciudin, A. Bonfanti, P. Aswath, G. Straffelini, S. Gialanella: Role of the friction layer in the high-temperature pin-on-disc study of a brake material, Wear, Vol. 346-347, 2016, pp. 56-65

[36] T. Singh, C. I. Pruncu, B. Gangil, V. Singh, G. Fekete: Comparative performance assessment of pineapple and Kevlar fibers based friction composites, Journal of Materials Research and Technology, 2019, https://doi.org/10.1016/j.jmrt.2019.11.074 